\title{
H5N1 influenza outbreak during March 2006 in Jordan
}

\author{
Mohammad Q. Al-Natour ${ }^{1^{*}}$, Mahmoud N. Abo-Shehada ${ }^{2}$ \\ ${ }^{1}$ Avian Diseases Research Laboratory, Department of Veterinary Pathology \& Public Health, Faculty of Veterinary Medicine, \\ Jordan University of Science and Technology, Irbid, Jordan; ${ }^{*}$ Corresponding Author: alnatour@just.edu.jo \\ ${ }^{2}$ Department of Basic Veterinary Medical Sciences, Faculty of Veterinary Medicine, Jordan University of Science and Technology, \\ Irbid, Jordan
}

Received 2 October 2012; revised 3 November 2012; accepted 11 November 2012

\section{ABSTRACT}

The highly pathogenic avian influenza H5N1 pandemic motivated countries around the World to be prepared for outbreaks within their borders. Well ahead of the outbreak, in Jordan contingency plans were prepared involving all relevant bodies in both the private and public sectors and a practice was simulated to test the effectiveness of the task force and the applicability of the plan. The highly pathogenic H5N1 influenza virus was detected and confirmed in one turkey in a backyard flock comprising 12 turkeys and 25 chickens in Kufranjah, 6 km from Ajloun city, on 23 March 2006. The samples were confirmed by the following day. Control measures were implemented immediately according to the national contingency plan and complete clean up achieved by 27 March 2006. A 3 km area around the index case was designated as a control zone, with a $10 \mathrm{~km}$ area around the holding further designated as a surveillance zone. The objective was to stamp out the infection and approximately 20,000 birds were destroyed including all commercial and backyard flocks in the control zone. All the human contacts were examined, treated and discharged from the hospital. The immediate response from all Jordanian sectors involved in the control strategy was positive as a result of increasing awareness and training programs that were implemented six months before the occurrence of the outbreak. $A$ total estimated economic loss posed by this outbreak including compensation was almost \$US169 million. Following the outbreak, passive surveillance for the virus was undertaken and training and capacity building continued. Efforts made in the preparation for an outbreak paid dividends and the need for a department responsible for monitoring migratory and wild birds in Jordan was recognized. Legislation regarding biosecurity of poultry farms and poultry transport vehicles should be revised.

Keywords: Avian Influenza; HPAI H5N1; Turkey; Poultry; Jordan; Outbreak; Control Strategy

\section{INTRODUCTION}

During the last century the world experienced three pandemics of influenza type A. The first was the Spanish flu, in 1918-1919 identified as Influenza A H1N1 and lead to 20 - 40 million deaths worldwide in 6 months affecting young healthy adults between 20 - 40 years of age [1-3]. The second was the Asian flu, in 1957-1958 caused by Influenza A H2N2, identified in China in February, 1957 reaching the USA by June 1957 causing approximately 70 thousand deaths there. Elderly people had the highest mortality but after 10 years the causative virus disappeared from human population. The third pandemic was the Hong Kong flu which occurred during 1968-1969 and caused by Influenza A H3N2 first detected in early 1968 in Hong Kong, spread to the USA later in that year, with a death toll of $\sim 34,000$ people $[1,3]$. Only H1N1 may be derived from an avian source [3], while the other two represent reassortants between both avian and human strains. The current H5N1 is still reported in many countries affecting avian and mammalian species (Table 1). The latest pandemic virus in 2009 was due to a swine origin influenza A virus S-OIV H1N1 derived from avian to mammalian cross species transmissions [4]. All outbreaks of the highly pathogenic avian influenza (HPAI) are caused by influenza A subtypes $\mathrm{H} 5$ and $\mathrm{H} 7$ [5]. Outbreaks of these viruses in poultry were rare events before 2003 with only 24 primary outbreaks of $\mathrm{H} 5$ and $\mathrm{H7}$ subtypes have been reported worldwide since 1959, occurring mainly in Europe and the Americas [6].

The ongoing HPAI H5N1 is unique in spreading to many countries compared with the previous outbreaks. There have been outbreaks of H5N1 in East- and Middle- 
Table 1. Confirmed HPAI-H5N1 outbreaks in domestic poultry (DP) and other animals and number of deaths and cases in humans (As of August, 10, 2012).

\begin{tabular}{|c|c|c|c|c|c|}
\hline \multirow{2}{*}{ Area } & \multirow{2}{*}{ Country } & \multicolumn{2}{|c|}{ Outbreak date } & \multirow{2}{*}{ Other species affected } & \multirow{2}{*}{ No. of human (Deaths/cases) } \\
\hline & & First & Latest & & \\
\hline \multirow[t]{7}{*}{ Near East } & Iraq & Jan, 18, 2006 & Feb, 1, 2006 & DP-wild birds & $2 / 3$ \\
\hline & Iran & Feb, 2, 2006 & Oct, 17, 2011 & DP-wild birds & - \\
\hline & Kuwait & Feb 232007 & Apr, 20, 2007 & DP-Wild birds-zoo birds & - \\
\hline & Saudi Arabia & Mar, 12, 2007 & Jan, 29, 2008 & DP-only & - \\
\hline & Israel & Mar, 16, 2006 & Mar, 13, 2012 & DP-Emu (Zoo) & - \\
\hline & West Bank \& Gaza Strip & Mar, 21, 2006 & Feb, 27, 2011 & DP-only & - \\
\hline & Jordan & Mar, 23, 2006 & Mar, 23, 2006 & DP-only & - \\
\hline \multirow[t]{3}{*}{ Africa } & Nigeria & Jan, 16, 2006 & Jul, 22, 2008 & DP-Wild birds & $1 / 1$ \\
\hline & Egypt & Feb, 17, 2006 & Mar, 27, 2012 & DP-Wild birds-donkeys & $60 / 168$ \\
\hline & Djibouti & Apr, 6, 2006 & Apr, 6, 2006 & DP-only & $0 / 1$ \\
\hline \multirow[t]{9}{*}{ Asia } & Viet Nam & Jan, 9, 2004 & Feb, 20, 2012 & DP-only & $61 / 123$ \\
\hline & Cambodia & Jan, 12, 2004 & Nov, 3, 2011 & DP-wild birds & $19 / 21$ \\
\hline & Lao PDR & Jan, 15, 2004 & Apr, 27, 2010 & DP-only & $2 / 2$ \\
\hline & China (Hong Kong SAR) & Jan, 192004 & Mar, 15, 2012 & DP-wild birds & $28 / 43$ \\
\hline & Thailand & Jan, 23, 2004 & Nov, 10, 2008 & DP-wild birds-tiger & $17 / 25$ \\
\hline & Indonesia & Feb, 2, 2004 & Mar, 2012 & DP-pigs (no clinical signs) & $159 / 191$ \\
\hline & Bangladesh & Feb, 5, 2007 & Mar, 28, 2012 & DP-only & $0 / 6$ \\
\hline & Pakistan & Feb, 23, 2006 & Jun, 17, 2008 & DP-wild birds & $1 / 3$ \\
\hline & Myanmar & Mar, 8, 2006 & Mar, 5, 2012 & DP-only & $0 / 1$ \\
\hline \multirow[t]{3}{*}{ Europ } & Azerbaijan & Feb, 2, 2006 & Mar, 18, 2006 & DP-wild birds-dogs & $5 / 8$ \\
\hline & Turkey & Oct, 1, 2005 & Mar, 9, 2008 & DP-wild birds & $4 / 12$ \\
\hline & Total & & & & 359/608 (59\%) \\
\hline
\end{tabular}

Sources: OIE, European Commission (EC), FAO and national governments-WHO/GIP for human deaths/cases.

Asia, Europe and Africa since 2004 resulting in devastating losses to the poultry industry [2]. Influenza viruses are members of the Orthomyxoviridae family and structurally they are enveloped in $20 \%$ lipid and segmented with 8 segments coding for 10 proteins having a single stranded negative sense RNA that are classified into three types; A, B and C. These types are also divided into subtypes based on serogrouping of 16 hemagglutinin (HA) and 9 neuraminidase (NA) genes [7,8]. These viruses have 144 possible combinations based on the HANA as a result of replication of 2 viruses in a single cell. Type A viruses infect both avian and mammalian species. The HPAI subtype H5N1 is a major international concern being a threat to the poultry industry causing devastating economic losses and the death of many people worldwide.

More than 400 million domestic poultry have been culled or killed at an estimated cost of \$US 20 billion worldwide since 2003. There have been twenty-two confirmed reports of human cases in six countries (Bangladesh, Cambodia, China, Egypt, Indonesia and Vietnam) and 18 confirmed wild bird events in China (Hong Kong), India and Nepal [9]. The cumulative human case fatality rate reached 59\% (359 deaths/608) human infections between 2003 and 2012 in 15 countries as reported by WHO [10] and summarized in Table 1. In 2006 the human case fatality rate was $68.7 \%$ (79/115). Turkey was the first Middle Eastern country to detect HPAI- H5N1 in October 2005 [11]. By March 2006, many Middle Eastern countries including; Egypt, Iraq, Iran, Israel, Palestinian Territories, Jordan [11], Saudi Arabia [12,13] Kuwait $[12,14]$, reported the virus. HPAI H5N1 was detected in poultry in Jordan on 23 March, 2006, [9,14]. This is a study of the events around the HPAI H5N1 out- 
break in Jordan in March 2006, Jordanian alert preparation pre outbreak, and measures used to contain the outbreak without spreading to additional geographic area in the country and post outbreak strategies and alert preparedness to date.

\section{THE JORDANIAN HPAI H5N1 OUTBREAK}

\subsection{Pre-Outbreak Preparedness}

The Jordanian government prepared a contingency plan to be implemented in the event of an outbreak. This plan defines the specific role of every organization. It was a result of joint efforts from different governmental and non-governmental sectors in the country including health, agriculture, local government and the media.

In the event of outbreak veterinary and medical syndicates, the poultry industry, the Jordanian police and public defense forces, municipalities and other related organizations were ready to execute their role as appropriate. The Ministry of Health $(\mathrm{MoH})$, including the Department of Public Health, task force was assigned to hospitals in each governorate to deal with patients with suspected respiratory diseases, while the Ministry of Agriculture (MoA), including the Veterinary Department, task force concentrated on the prevention of AI occurrence and control strategies in the case of an outbreak in birds. A budget of US $\$ 8.5$ million was allocated by the Prime Minister's Office to initiate the different programs for prevention and control strategies. Training programs for the teams including laboratory diagnostics for the medical and veterinary sides and public awareness were ready six months before the March 2006 outbreak.

\subsection{Veterinary and Public Health Measures Taken before the Outbreak of Avian Influenza (H5N1) in Jordan}

The government contingency plan was drawn up, the Jordanian MoA in collaboration with other ministries and agencies to combat and control an outbreak of the disease. This plan defines a specific role for every organization on an outbreak when an operations room would organize a field work schedule. This room would be linked to armed forces and national security operations rooms so it can manage the situation in any part of the kingdom [15].

The Jordanian MoH assigned 20 public \& private hospitals over the whole country for admitting suspected human cases. In addition Al-Basheer in Amman (MoH) and King Abdulla the II in Irbid were assigned as reference hospitals for confirmation. Each hospital kept one floor with high biosecurity [15].

\subsection{Capacity Building and Training Programs}

Capacity building including $\mathrm{MoH}$ hospitals, equipment, disposables, avian influenza diagnostic kits including PCR and Real time PCR, anti-influenza drugs (Tamiflu) and antibiotics, disinfectants, antiseptics, and protective clothing were emplaced appropriately.

Training program was initiated for medical doctors, nurses and allied teams on case management and laboratory diagnosis.

The Veterinary Department in the MoA carried out all capacity building steps for clinics and diagnostic laboratories in terms of equipment, materials and disposables needed.

Training programs were given for all teams from all departments involved on how to implement their assigned tasks when an outbreak of Avian Influenza occurs. The whole task force team executed an exercise on one farm in Al-Mafraq Governorate prior to the outbreak.

Public awareness and media coverage; regular seminars, conferences, lectures for students at universities and schools, associations in cities and villages in most parts of Jordan were delivered during 2005. In addition, information has been dispersed through the Jordanian media with messages in daily newspapers, leaflets, TV and radio broadcasts. One government media spokesman was assigned to the media [15]. A book on bird flu in Arabic was prepared and published in early 2006 and included information for every citizen [16].

Each governorate assigned their working team according to the national plan as follows;

1) Security team controlling all roads and highways, from the index farm outward covering circles of $3 \mathrm{~km}, 7$ $\mathrm{km}$ and $10 \mathrm{~km}$ radius in order to prevent bird movement.

2) Disposing team-humanely killing birds at foci, sanitary disposal of poultry at assigned location, going outward from the index farm within a circle of $3 \mathrm{~km}$ radius.

3) Disinfecting team-following the disposing team to disinfect farms and premises after them.

4) Water team-providing water tanks trucks with pressurized water for cleansing and disinfection.

5) General health team-following contact persons, and rescues, dealing with human suspected cases sending them to hospitals where appropriate.

6) Poultry vaccination team-ready to vaccinate birds according to the MoA decision.

7) Media team-informing local TV, Radio stations and press.

8) Logistics-providing logistical support for each team [15].

\subsection{Outbreak Description}

Jordan is bordered by Syria in the north, Saudi Arabia 
in the south, Iraq and Saudi Arabia in the east and Israel and the West Bank in the west (Figure 1). On Thursday 23, March 2006, a suspected avian influenza case in a backyard flock located in Kufranjah Village, Ajloun Governorate was investigated. The Ajloun Governorate has an area of $420 \mathrm{~km}^{2}$, representing $0.5 \%$ of the total area of the country and with a population of 132,000, is bordered by the populous governorates of Irbid from north and west and Balqa from the south, also Jarash from the east and the Jordan Valley on the west (Figure 2).

Ajloun has 85 broiler farms representing 3\% of the country's total with a density 0.2 farms per $\mathrm{km}^{2}$, with a capacity of 0.63 million birds ( $2 \%$ of the country's total, density 1500 birds per $\mathrm{km}^{2}$ ), there are 3110 backyard birds of a total of $173.83 \mathrm{~K}$ (1.8\% of the total backyard birds in Jordan) in 156 backyard flocks of a total of 8624 flocks $(1.81 \%)$ [17,18]. Only 2 broiler farms housing 17,000 birds and 3110 backyard birds were within the control zone (density of 711 birds per $\mathrm{km}^{2}$ ) and were located in the governorate.

The index backyard poultry flock had 12 turkeys and 25 chickens. Sporadic deaths among turkeys occurred during the 4 days before 23 March 2006. Twelve turkeys died (100\% mortality) the last being the only carcass available for testing. A complete case history form was taken before necropsy and laboratory procedures for confirmative diagnosis. Samples were sent to central veterinary laboratory, MoA, Amman on the same day.

Officials were informed of the suspected case and the Action Plan was implemented by the avian influenza task force teams. The sampling team started active surveillance in the vicinity of the suspected backyard flock. The suspected turkey samples were tested and proved positive by the rapid test (Capture ELISA) by noon, and confirmed using Real Time PCR for genes A, H5 and N1 later on the same day. Positive samples were sent to OIE reference laboratory on March 31.

The contingent from the Department of Public Health visited the family of the infected flock and sent the whole in family to the assigned hospital in Ajloun. Only one family member had a headache and all the family were treated with antibiotics and Tamiflu and were released from the hospital. There were no human cases or deaths.

To date Jordan has witnessed one case of H5N1 in a man from a neighboring country who arrived at Jordanian border and was checked by the Public health team because of a fever. Hospitalization and further lab tests confirmed H5N1 for which the patient was successfully treated and returned to his home country after 14 days.

\subsection{Controlling Strategy of the Outbreak}

Quarantine and Control measures were implemented immediately according to the national contingency plan and the clean-up completed by 27 March 2006. The armed forces and state police controlled all the roads around the index case by the early morning of the Friday 24 March 2006 in the 3 designated zones. A $3 \mathrm{~km}$ area around the Index case (A) was designated as a control zone (protection zone), and from $3-7 \mathrm{~km}$ radius (B)

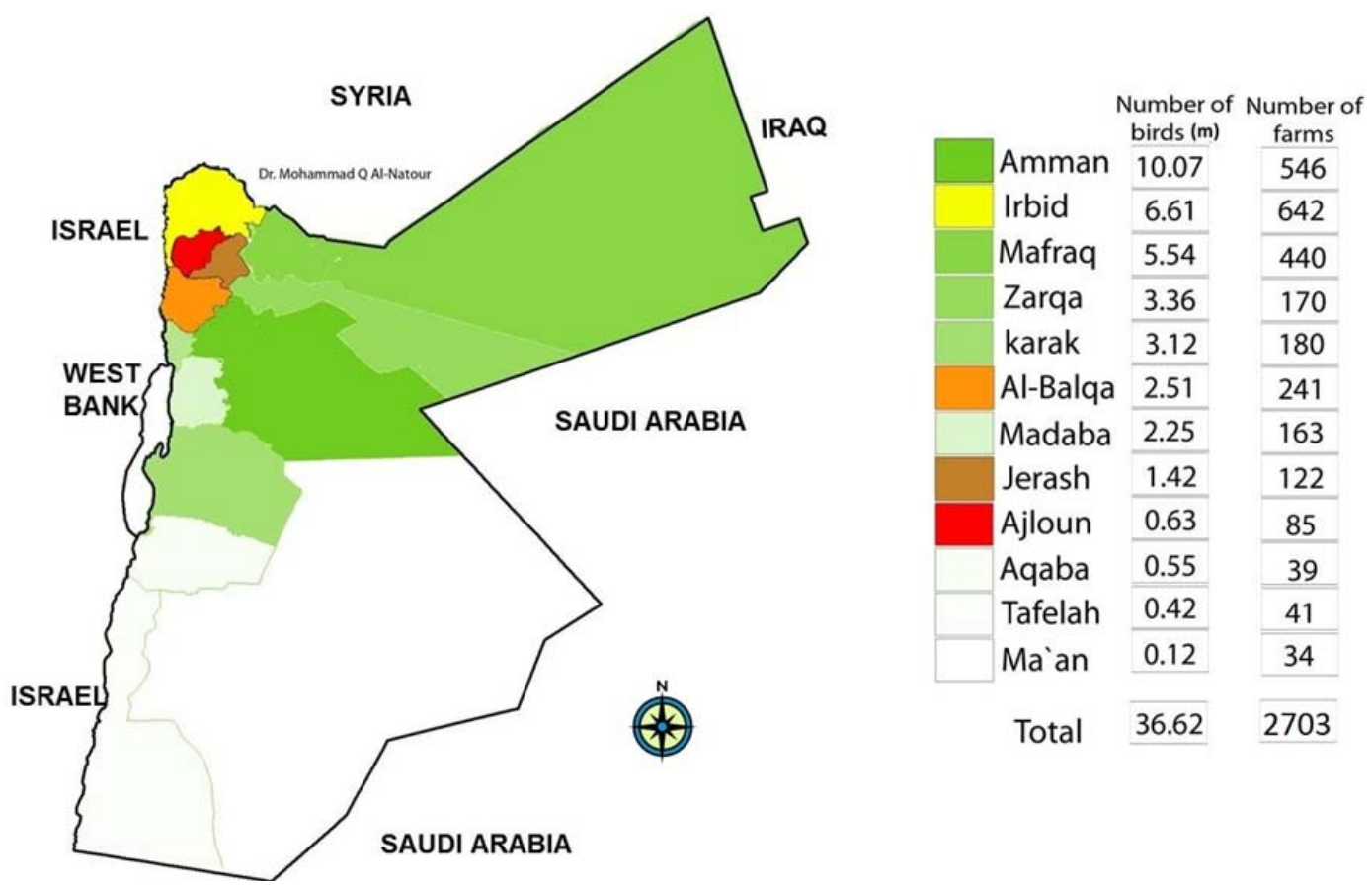

Figure 1. Number of poultry farms and their capacity (Million birds) in the Jordanian Governorates [17]. 


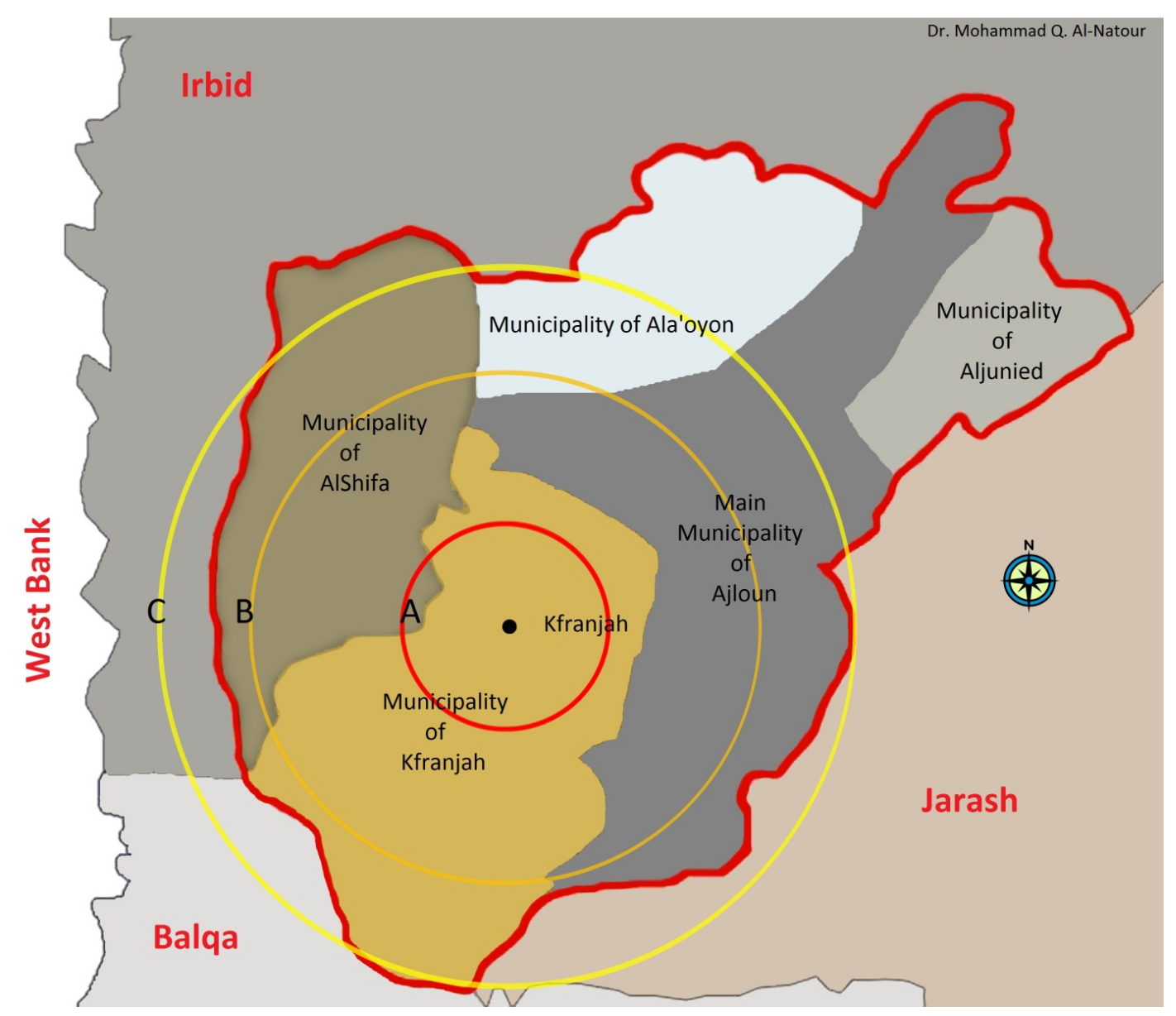

A: Red circle: $3 \mathrm{~km}$ radius around the index location; stamping out. B: Amber circle: 3 - 7 km radius; stamping out of backyard flocks instead of vaccination. C: Yellow circle: 0 - 10 km radius: Live bird market shutdown, stamping out backyard flocks then active surveillance.

Figure 2. Location of the index holding in Kufranjah village and the extend of the control zones of 3 circles of 3,7 and $10 \mathrm{~km}$.

further (vaccination and surveillance zone), a $10 \mathrm{~km}$ area radius (C) around the index case further designated as a surveillance zone (Figure 2). Stamping out rather than active surveillance was adopted. The live bird market was shut down on Friday 24 March 2006 within the 10 $\mathrm{km}$ radius from the index case. The designed national plan was followed.

The stamping out operation was started with two teams on Friday 24 March 2006 commencing on the index holding and working progressively outwards (2 teams). Four teams were employed on the 25 and six on the 26 March 2006. Each team comprised of a veterinarian, 2 policemen, drivers and 10 municipality workers, utilizing a lorry, a tractor and trailer and equipment for protection and disinfection.

Euthanasia of backyard birds was undertaken by atlanto-occiptal dislocation. On broiler farms "Lanete" a strychnine based pesticide was used in drinking water. Dead birds were placed in plastic bags, tied then placed in a lorry that made one trip to designated burial site on the same day then washed and disinfected there.

Poultry contact areas/yards or farm were cleaned and sprayed with disinfectant. Litter, feathers, and other contact material was bagged, loaded on the lorry and sent to the burial site. The disinfectants used were "Glutarex" (formaldehyde based) and "Ger-mlod" (Iodine based).

The designated burial site was identified on land owned by the Ajloun Municipality, and $5 \mathrm{~km}$ from the index holding case. The burial pit was at least $2 \mathrm{~m}$ wide, $4 \mathrm{~m}$ long and $2 \mathrm{~m}$ deep. At the end of each day birds in plastic bags were placed in the burial pit, covered with limestone and then soil $(40 \mathrm{~cm})$. Stamping out operations within the control zone were followed by sanitary land fill and completed by Monday 27 March 2006.

\subsection{Post-Outbreak}

Emphasis was placed on bio-security training and workshops sponsored by the MoA, FAO, and other international agencies in Jordan were put on for veteri- 
narians, agriculture engineers, and other allied teams in the avian influenza task force. These training workshops were executed in many universities and at the Department of Animal Health (MoA). Training the trainers was the first step in order to instruct other poultry workers in the country.

The vaccination of breeders and layers was optional for owners; however, backyard flocks were vaccinated with monovalent H5N2 inactivated vaccine. The MoA provided the vaccine and the vaccination crew free of charge for backyard flocks. A vaccine stock of 3940 vials each of 1000 doses was available at the MoA. The MoA do not recommend vaccination for broiler farms because of public acceptance and the short lifespan of broilers.

Two laboratories were assigned for virus isolation. Active surveillance [19] was carried out by onsite visits by veterinarians and other members of avian influenza task force teams in the Ajloun Governorate covering all poultry farms. The team followed written instructions for the field farm visit; which included the completion of a flock history form. Sampling forms included the type of sample taken and number of samples per farm. To date all visited and sampled farms proved negative for H5N1 by laboratory tests.

Veterinarians and members of avian influenza task force in each governorate of Jordan conducted passive surveillance [20]. Poultry farm owners were to report daily mortalities to veterinary departments in their governorate. The poultry veterinarian paid visits to farms with high mortality and/or a decrease in egg production. The same procedure above was followed regarding sample collection and laboratory investigations. To date all active and passive surveillance received negative results for H5N1 avian influenza. More than 3000 farms were visited and more than 1500 samples tested negative by PCR and Real-time PCR in 2006 [21]. Passive surveillance has been going on continuously from 2006 to date. The country was declared HPAI free by the OIE on 27 June 2006.

Communication between the different elements of the Jordanian Avian Influenza Task force was very quick and transparent utilizing cell phones, fax, land line phones and emails. Communication with the Jordanian public was also transparent with daily updates via the local media. In addition hot line telephone numbers were provided for the public and emergencies. Continuous exchange of information with the bordering countries, international agencies (FAO, WHO, OIE, etc.) pre- and post-outbreak was adopted.

The total cost of the outbreak in Jordan was calculated using data obtained from official governmental sources (Table 2) and estimated at $\$ 168.992$ million US dollars based on data obtained from [17,18,21]. This included direct costs, indirect costs, urgent governmental expenses, and long term costs for 2007.

The concerned governmental departments are closely following the situation of H5N1 around the world and any updates concerning the control and prevention of this infection. There is still passive surveillance in all Jordanian governorates including commercial poultry farms, backyard flocks, zoos, bird shops, dead migratory waterfowl and resident birds.

\section{DISCUSSIONS}

\subsection{Al Introduction and Spread}

An outbreak of AI in an AI free country is a result of the introduction of AI virus into the country. The main route of AI virus introduction to a country is through infected migratory or wild birds. Other routes may include imported infected poultry and poultry products accompanied with failure of import regulations and quarantine measures.

In the Ajloun outbreak, there was no history of imported poultry or poultry products. This area has spring water sources which lie on the route of migratory birds which were seen at the time of the outbreak around the index backyard holding. Also, Ajloun is only $11 \mathrm{~km}$ from the border with West bank that had an outbreak of AI at the time and infected wild bird may have visited the outbreak holding.

Alternatively the introduction of the virus to a farm/ holding can be the result of a biosecurity failure within the poultry population. It is well known that biosecurity includes expensive measures taken to protect the birds but no farmer will spend more than the value of the bird on such measures and in backyard poultry minimal measures, if any, are taken. The infected holding did not practice any biosecurity measures.

The species involved in Ajloun outbreak was the turkey which is known to be a highly susceptible species to AI.

The risk of the spread of influenza viruses in a country depends on many factors. High bird population density including commercial, resident and migratory waterfowl is a factor shared by many endemic countries; e.g. China, Egypt, Vietnam, and others. The type of bird species produced by the local poultry industry can influence the prevalence of the virus, for example duck and turkey. The duck serves as a reservoir host to AI viruses and the turkey is known to be more susceptible than the chicken. In Ajloun, the poultry density was 1500 birds per $\mathrm{km}^{2}$ and fortunately the density of birds was less than half of that, 711 birds per $\mathrm{km}^{2}$ in the outbreak control zone. Using the Read-Frost model with this density as the number of susceptible birds, 0 birds as immune birds and probability of contact $=0.01$ predicted total population 
Table 2. Estimated economic losses in the Jordanian poultry industry in 2006 due to H5N1 outbreak.

\begin{tabular}{|c|c|c|}
\hline Cost & Items & Million \$US \\
\hline \multirow[t]{6}{*}{ Direct } & Stamping out \& compensation & 0.128 \\
\hline & Broiler industry & 52.26 \\
\hline & Layer industry & 18.36 \\
\hline & Breeder farms \& fertile eggs & 7.97 \\
\hline & Imported H5 vaccines in 2005 & 4.24 \\
\hline & Total & 82.96 \\
\hline \multirow[t]{9}{*}{ Indirect } & Decreased in consumer demand for poultry products & 9.89 \\
\hline & Decreased production as a result of decreased poultry price & 3.78 \\
\hline & Biosecurity & 1.64 \\
\hline & Export (Fertile eggs) as we export 20 million egg/year & 4.9 \\
\hline & Decrease in backyard flocks and thus income losses & 1.4 \\
\hline & Trader’s \& marketing agent’s loss & 0.63 \\
\hline & Pet animal shops & 2.1 \\
\hline & Tourism & 17.5 \\
\hline & Total & 41.84 \\
\hline \multirow{3}{*}{ Urgent Expenditure’s } & Appointment of new staff, training, equipment's \& cars & 3.95 \\
\hline & Vaccination campaign for backyard flocks & 0.042 \\
\hline & Total & 3.992 \\
\hline Total & Urgent, direct \& indirect cost & 128.792 \\
\hline \multirow[t]{9}{*}{ Long Term } & Strategic studies \& consultations & 4.2 \\
\hline & Migratory bird watch \& surveillance & 2.1 \\
\hline & Biosecurity \& subsidies & 4.2 \\
\hline & Poultry sector investment & 24.5 \\
\hline & Training programs & 0.7 \\
\hline & Diagnostic laboratories & 2.8 \\
\hline & Animal health network & 1.00 \\
\hline & Vaccines and vaccination for backyard flocks & 0.7 \\
\hline & Total & 40.2 \\
\hline Grand Total & & 168.992 \\
\hline
\end{tabular}

Estimated losses were calculated based on production and average onsite farm prices/year. One \$US = 0.708 Jordanian Dinar (JD). Data obtained from [17, $18,21]$.

infection after approximately 12 weeks. The bird density in zoos, bird shops and live bird markets pose a risk to workers and to other birds. Generally Jordan does not produce turkeys or ducks commercially and has only one zoo in Amman. Commercial poultry farms in Jordan are mostly chicken farms with 3 ostrich and one quail farm. However backyard poultry often include local chickens, turkeys, ducks, geese and pigeons with caged birds in avian shops and live bird markets which sell live chickens and other birds.

\subsection{Pre-Outbreak Preparedness}

The historic devastating effects of the AI virus on the economy of the poultry industry and loss of human life especially recently in the Far East has motivated the international community to cooperate to control the growing pandemic of AI. With the cooperation of these entities and the solidarity of the Jordanian Administration uniting and society, Jordan prepared well and conducted a rehearsal for an AI outbreak ahead of the virus out- 
break. The Jordanian plan for preparedness used OIE/ WHO/FAO guidelines tailored to Jordan.

\subsection{Outbreak Containment}

During the outbreak the same spirit of cooperation as during the preparation was maintained and the task force accomplished it's mission. The virus was identified within 24 hours of the first suspicious case and samples were sent for confirmation to regional and international laboratories. Control zones were drawn and all backyard and commercial poultry were destroyed and bird movements controlled. Attention to in contact human health was executed successfully with no development of human cases.

The installed measures together with the low density of birds in the control zone were instrumental in stopping the virus spread beyond the index holding.

\subsection{Post Outbreak Strategy to Date}

In spite of the fact that Jordan lies on the migratory route of many species of birds that may carry the virus [22], the vaccination strategy followed by MoA against H5N1 in Jordan is compulsory for backyards flocks and optional for commercial chicken farms. The vaccine in use is the inactivated H5N2. This strategy, together with the strengthened biosecurity measures adopted by the farmers, helped stop further introduction of the virus, maintaining the AI free status.

\subsection{Lessons Learned}

Stringent training for field and laboratory veterinarians and other workers, developing the contingency plan and cooperation with all concerned departments and workers in the public and private sectors as one health team made Jordan capable of controlling the outbreak. Jordan preparedness, quick laboratory identification, rapid response to the index case, and the cooperation with OIE reference lab at Padova, Italy, and other regional laboratories in Egypt were crucial factors in controlling the outbreak.

In Jordan, migratory waterfowl and resident wild birds are monitored by the Royal Society for the Conservation of Nature (RSCN). Establishing a responsible department for monitoring the health of migratory and wild birds can be a useful frontline against the introduction of pathogens spread via wild birds.

Quarantine facilities for poultry must be installed, revised and updated at relevant ports of entry into the country. The movement of birds in open trucks is a common practice in Jordan but the international specifications for poultry transport vehicles must be enforced by legislation and put into practice. Only licensed poultry slaughter houses following hazard analysis and critical control points (HACCP) with trained meat inspectors should be used.

Updating biosecurity measures outlined by the MoA and adoption by farmers and budgeting for the prevention of AI outbreaks must be in line with the fact that preventing the disease is the first line of defense. This outbreak cost Jordan US \$168.992 million.

Although contingency plans are ready for implementation in the event of another outbreak, they should beupdated with information gained from lessons learned from the previous outbreak and routinely revised. As trained people leave their jobs over time, there is a need to train new staff and buy updated equipment and supplies. Budget allocation must also be revised and not compromised in the absence of outbreaks.

\section{CONCLUSION}

Forming a cooperative task force and plans for AI control raises the level of preparedness and success in controlling AI outbreaks. Continuing AI surveillance, improving biosecurity levels on poultry farms/holdings, regional and international cooperation, routine training, revision and updating of adopted health management and measures are fundamental to controlling disease outbreaks. Quick virus identification, confirmation and response to an outbreak according to pre-prepared plans determine subsequent spread to other holdings.

\section{ACKNOWLEDGEMENTS}

The authors would like to thank Jordan University of Science and Technology, the Jordanian MoA and $\mathrm{MoH}$, the FAO-Jordan Drs L. Sawalha, M. Mazahreh, N. Amarin, H. Maeitah, M. Al-Hadidi, O. Abed and H. Al-Natour for their support.

\section{REFERENCES}

[1] Goldrik, B.A. and Goetz, A.M. (2007) Pandemic influenza: What infection control professional should know. American Journal of Infection Control, 35, 7-13. doi:10.1016/j.ajic.2006.04.203

[2] Kalthoff, D., Globig, A. and Beer, M. (2010) (Highly pathogenic) avian influenza as zoonotic agent. Veterinary Microbiology, 140, 237-245. doi:10.1016/j.vetmic.2009.08.022

[3] Belshe, R.B. (2005) The origin of pandemic influenzalessons from the 1918 virus. New England Journal of Medicine, 353, 2209-2211. doi:10.1056/NEJMp058281

[4] Zimmer, S.M. and Burke, D.S. (2009) Historical perspective-emergence of influenza A (H1N1) viruses. New England Journal of Medicine, 361, 279-285. doi:10.1056/NEJMra0904322

[5] Alexander, D.J. (2007) An overview of the epidemiology of avian influenza. Vaccine, 25, 5637-5644. doi:10.1016/j.vaccine.2006.10.051

[6] Werner, O. and Harder, T.C. (2006) Avian influenza. In: 
Kamps, B.S., Hoffmann, C. and Preiser, W., Eds., Influenza Report 2006, Flying Publisher, Paris, 48-88.

[7] Webster, R.G., Bean, W.J., Gorman, O.T., Chambers, T. M. and Kawaoka, Y. (1992) Evolution and ecology of influenza A viruses. Microbiology Review, 56, 152-179.

[8] Fouchier, R.A., Munster, V., Wallensten, A., Bestebroer, T. M., Herfst, S., Smith, D., Rimmelzwaan, G.F., Olsen, B. and Osterhaus, A.D. (2005) Characterization of a novel influenza A virus hemagglutinin subtype (H16) obtained from black-headed gulls. Journal of Virology, 79, 28142822. doi:10.1128/JVI.79.5.2814-2822.2005

[9] EMPRES/FAO-GLEWS (2012) H5N1 HPAI global overview. EMPRES, 31, 1-11. http://www.fao.org/docrep/015/an388e/an388e.pdf

[10] World Health Organization (WHO) (2012) Cumulative number of confirmed human cases of avian influenza A/ (H5N1) reported to the WHO. http://www.who.int/influenza/human animal interface/E N_GIP_20120810CumulativeNumberH5N1cases.pdf

[11] Williams, R.A.J. and Peterson, A.T. (2009) Ecology and geography of avian influenza (HPAI H5N1) transmission in the Middle East and Northeastern Africa. International Journal of Health Geographics, 8, 47.

http://www.ij-healthgeographics.com/content/8/1/47 doi:10.1186/1476-072X-8-47

[12] Marjuki, H., Wernery, U., Yen, H.L., Franks, J., Seiler, P., Walker, D., Krauss, S. and Webster, R.G. (2009) Isolation of highly pathogenic avian influenza H5N1 virus from Saker Falcon (Falco cherrug) in the Middle East. Advances in Virology, 2009, 1-7.

http://www.ncbi.nlm.nih.gov/pubmed/20148178 doi: $10.1155 / 2009 / 294520$
[13] Alkhalaf, A.N. (2010) Field investigation on the prevalence of avian influenza virus infection in some localities in Saudi Arabia. Pakistan Veterinary Journal, 30, 139142.

[14] Al-Azemi, A., Bahl, J., Al-Zenki, S., Al-Shaji, Y., AlAmad, S., Chen, H., Guan, Y., Peiris, J.S.M. and Smith, G.J.D. (2008) Avian influenza A virus (H5N1) outbreaks, Kuwait, 2007. Emerging Infectious Diseases, 14, 958-961. doi:10.3201/eid1406.080056

[15] Anon (2012) The national plan for influenza preparedness. 7th Edition, The Hashemite Kingdom of Jordan, 1-83.

[16] Abo-Shehada, M.N. and Al-Natour, M.Q. (2006) Avian flu (in Arabic), Al-Isara University Publications, Amman.

[17] Anon (2005) Annual report. Ministry of Agriculture.

[18] Anon (2006) Annual report. Ministry of Agriculture.

[19] Thrusfield, M. (2007) Veterinary epidemiology. 3rd Edition, Blackwell Science Ltd., Oxford. www.blackwellpublishing.com

[20] Sims, L. (2007) Achievements, issues and options on strategies for HPAI control and prevention. Technical meeting on Highly Pathogenic Avian Influenza and Human H5N1 infection technical report FAO of the UN, WHO and OIE with the collaboration of UNSIC and UNICEF Guidelines for the surveillance of avian influenza. OIE Manual Chapter 3.8.9. http://www.oie.int/eng/normes/mcode/en chapitre 3.8.9. $\underline{\mathrm{htm}}$

[21] Anon (2007) Annual report. Ministry of Agriculture.

[22] Andrews, I.J. (1995) The birds of the Hashemite Kingdom of Jordan. Burns and Harris (Print) Limited, Dundee. 